\title{
Estudo de intervenção sobre a divisão: ilustrando as relações entre metacognição e aprendizagem ${ }^{1}$
}

\section{An interventional study about division: Illustrating the relation between metacognition and learning}

\author{
Síntria Labres Lautert ${ }^{2}$ \\ Alina Galvão Spinillo ${ }^{3}$
}

\begin{abstract}
RESUMO
Discute-se um estudo de intervenção conduzido em um contexto experimental em que a interação adulto-criança era marcada por atividades metacognitivas com vistas a auxiliar na superação das dificuldades experimentadas por crianças com o conceito de divisão. As atividades metacognitivas propostas envolviam a tomada de consciência da criança sobre procedimentos adotados na resolução de problemas, sendo associada uma explicitação dos princípios invariantes do conceito de divisão. $\mathrm{O}$ estudo consistiu em um pré-teste e um pós-teste aplicado a 100 crianças de baixa renda ( 8 a 11 anos), alunas do $4 .^{\circ}$ ano do ensino fundamental de escolas públicas na cidade do Recife que apresentavam dificuldades com a divisão. As crianças foram distribuídas em um grupo controle e em um grupo experimental, havendo as crianças do grupo experimental participado
\end{abstract}

1 Este trabalho recebeu apoio do Conselho Nacional de Desenvolvimento Científico e Tecnológico (CNPq) sob forma de bolsa de estudos para realização de doutorado da primeira autora sob orientação da segunda autora.

2 Doutora em Psicologia Cognitiva pela Universidade Federal de Pernambuco, Professora Adjunta no Programa de Pós-Graduação em Psicologia Cognitiva, Departamento de Psicologia da Universidade Federal de Pernambuco, Brasil (Núcleo de Pesquisa em Psicologia da Educação Matemática - NUPPEM). E-mail: sintrialautert@gmail.com

3 Doutora em Psicologia do Desenvolvimento pela University of Oxford, Inglaterra, Professora Associada do Programa de Pós-Graduação em Psicologia Cognitiva, Departamento de Psicologia, da Universidade Federal de Pernambuco, Brasil (Núcleo de Pesquisa em Psicologia da Educação Matemática - NUPPEM) E-mail: alinaspinillo@hotmail.com 
da referida intervenção. As relações entre metacognição e aprendizagem são ilustradas a partir da apresentação e discussão de passagens extraídas das sessões de intervenção. Os resultados mostraram que no pré-teste os dois grupos não diferiam entre si, apresentando o mesmo nível de dificuldade; porém, após a intervenção, os participantes do grupo experimental superaram as dificuldades iniciais, o mesmo não sendo observado em relação aos participantes do grupo controle.

Palavras-chave: metacognição; aprendizagem, conceito de divisão; crianças; ensino fundamental.

\begin{abstract}
We discuss an interventional study carried out in an experimental context in which the adult-child interaction was characterized by metacognitive activities whose goal was to help children to overcome difficulties with the concept of division. The proposed metacognitive activities involved helping the child reach awareness of the procedures used in solving problems, associated with an explanation of the division invariable principles of the division concept. The study consisted of a pre- and post-test taken by 100 lower-class children aged 8 to 11 who were in the 4 th grade in public schools in Recife and presented difficulties with division. The children were divided into a control group and an experimental group. The children in the experimental group participated in the aforementioned intervention. The relation between metacognition and learning is illustrated by the presentation and discussion of passages taken from the intervention sessions. The results show that, in the pre-test, the two groups presented no differences, both of them presenting the same level of difficulties. However, after the intervention, participants in the experimental group overcame their initial difficulties, but this was not observed in the participants in the control group.

Keywords: metacognition; learning; concept of division; children; Elementary School.
\end{abstract}

\title{
Introdução
}

De maneira geral, sem detalhar diferenças derivadas de distintas afiliações teóricas, a metacognição pode ser entendida como o conhecimento acerca do próprio conhecimento, estando relacionada à tomada de consciência e à capacidade do indivíduo de monitorar e autorregular seus processos cognitivos 
(FLAVELL, 1976; 1979; 1987; PIAGET, 1977; 1978; STERNBERG, 2000; VYGOTSKY, apud COLE; JOHN-STEINER; SCRIBNER; SOUBERMAN, 1978). A metacognição pode ser ela própria objeto de pesquisa, como discutido por Seminério, Anselme e Chahon (1999), ou pode ser examinada como um fator mobilizador de aprendizagem e de desenvolvimento como enfatizam Spinillo (1999), Ribeiro (2003) e Jou e Sperb (2006). Esses dois enfoques não são exclusivos ou incompatíveis, porém revelam aspectos distintos de um fenômeno amplo e complexo.

O presente artigo se aproxima do segundo enfoque, pois, embora a metacognição não seja ela própria o fenômeno investigado, fica claro o fato de que este mecanismo cognitivo estava presente nas atividades propostas em um estudo de intervenção que tinha por objetivo desenvolver em crianças uma compreensão apropriada acerca do conceito de divisão.

Spinillo (1999) discute as relações entre aprendizagem e desenvolvimento a partir de pesquisas de intervenção realizadas no âmbito da psicologia. Aponta a metacognição como um mecanismo mobilizador de mudanças capaz de ativar processos de raciocínio apropriados frente a uma dada situação, propiciando o desenvolvimento de habilidades de autorregulação e gerenciamento para corrigir formas de raciocinar, permitindo o redirecionamento de formas de pensar. Segundo a autora, este mecanismo é mais frequentemente ativado em situações mediadas por um adulto do que em situações caracterizadas pela autodescoberta em que a criança dificilmente faria por si mesma uma reflexão desta ordem.

A metacognição como apoio a situações de ensino e aprendizagem foi considerada em diversos estudos nas mais diferentes áreas do conhecimento: a respeito da compreensão de textos (e.g., BORUCHOVITCH, 2001; LEFFA, 1996; SPINILLO, 2008), da aprendizagem da física (e.g., DAVIS; NUNES; NUNES, 2005; ROZENCWAJG, 2003) e da aprendizagem da matemática (e.g., CARDELLE-ELAWAR, 1992; 1995; CHAHON, 1999; GOLDBERG, 1999; MAVARECH; KRAMARSKI, 2003; MORO, 2005; SPINILLO, 2003).

Partindo dessa concepção a respeito das relações entre metacognição e aprendizagem, Spinillo (2003) relata uma experiência de ensino relativa ao conceito de proporção conduzida em sala de aula do $3 .^{\circ}$ ano do ensino fundamental em uma escola pública em Recife. A assistência da professora se baseava particularmente nos seguintes pontos: (i) dirigir a atenção dos alunos para os aspectos relevantes de uma dada situação-problema, explicitando-os; e (ii) colocar em evidência o pensamento e as ações dos alunos ao resolverem situações-problema que envolviam o raciocínio proporcional para sua resolução com base em estimativas e pontos de referência. Nesta experiência foi instaurado em sala de aula um ambiente de discussão que estimulava o aluno a refletir e a explicitar suas formas de raciocinar e proceder durante a resolução de problemas. 
A professora encorajava os alunos a comparar as diferentes formas de resolução dos problemas, fossem elas apropriadas ou inapropriadas. Em outras palavras, o pensamento e as ações dos alunos eram colocados em evidência, passando a serem alvo de discussões, comparações e análise, caracterizando, portanto, uma prática de ensino baseada em atividades metacognitivas. Segundo a autora, isso favorecia a emergência de formas mais apropriadas de resolver as situaçõesproblema que requeriam a proporção para sua resolução, bem como favorecia a capacidade dos alunos de avaliar, monitorar e gerenciar seus procedimentos de resolução, revendo e alterando suas próprias hipóteses quando inadequadas.

Tendo como foco as relações entre metacognição e aprendizagem, foi elaborado um estudo de intervenção que tinha por objetivo auxiliar crianças a superar suas dificuldades em relação ao conceito de divisão. Duas dificuldades que são usualmente documentadas na literatura foram especificamente consideradas na intervenção: (i) dificuldade em compreender as relações inversas entre o tamanho das partes e o número de partes em que o todo foi dividido; e (ii) dificuldade em lidar com o resto em problemas de divisão inexata.

\section{A investigação}

A investigação foi realizada com 100 crianças de baixa renda, com idade entre 8 e 11 anos, alunas do $4 .^{\circ}$ ano de escolas públicas na cidade do Recife que apresentavam dificuldades com a divisão, conforme dados obtidos em uma avaliação prévia. As crianças foram igualmente divididas em um grupo controle e um grupo experimental. As crianças do grupo experimental participaram individualmente de uma intervenção que consistia em um conjunto de atividades voltadas para o ensino da divisão, enquanto as crianças do grupo controle continuaram apenas com o ensino usual da divisão em sala de aula.

As atividades propostas na intervenção centravam-se nas relações inversas entre os termos da divisão e sobre o significado do resto em problemas de divisão inexata. As sessões seguiam uma sequência didática em que inicialmente a criança resolvia um problema de divisão, sendo solicitada a explicar a forma pela qual havia resolvido o problema (independentemente se correto ou incorreto); em seguida a examinadora fornecia feedback e explicações, questionava e levantava alternativas acerca das formas de resolução adotadas pela criança; por fim, explicitava as regras ou princípios invariantes da divisão que estavam sendo contemplados na atividade que a criança estava realizando. As sessões de intervenção foram gravadas em vídeo e posteriormente transcritas em pro- 
tocolos individuais. Foram selecionadas duas passagens extraídas de diferentes entrevistas realizadas com diferentes participantes do grupo experimental para ilustrar a natureza metacognitiva das atividades conduzidas na intervenção.

Passagem 1:

Esta passagem ilustra uma atividade cujo objetivo era tornar explícita a relação inversa entre os termos da divisão (número de partes e tamanho das partes). Esta atividade consistia na apresentação de um problema base do qual se derivavam outros problemas, na medida em que a examinadora aumentava ou diminuía o tamanho das partes ou o número de partes. Material concreto era disponibilizado; no caso da passagem a seguir, copos e bandejas plásticas de brinquedo eram colocados diante da criança.

Problema base: Viviane preparou 18 copos de suco para o lanche e quer servir 6 copos em cada bandeja. Quantas bandejas ela vai precisar?

$\mathrm{C}^{-4}$ (resolve com os objetos, colocando três copos em seis bandejas) Seis bandejas.

E- Explica para mim como você fez [busca explicação sobre como ela resolveu]

C- Eu dividi três copos para cada bandeja.

E- Mas no problema podia colocar três copos em cada bandeja? O que dizia no problema? [focaliza a atenção no enunciado do problema]

C- Coloca seis copos em cada bandeja.

E- Ah! Eu tenho que colocar seis copos em cada bandeja. Então, você tem que prestar atenção no problema, no que o problema está pedindo. Então, vamos fazer o que o problema está pedindo. Tem que ser seis copos em cada bandeja.

C- (resolve novamente com os objetos colocando seis copos em três bandejas)

E- Quantas bandejas ela vai precisar?

C- Três.

E- Três bandejas. Muito bem! Gabriel ${ }^{5}$, quando a gente está fazendo um problema devemos prestar atenção no enunciado, o que está dizendo o problema, senão a gente termina respondendo errado. [novamente focaliza o enunciado].

Variação 1: "Gabriel, a Viviane resolveu aumentar a quantidade de copos nas bandejas. Ela não quer mais colocar seis copos em cada bandeja. Ela

4 Convenções adotadas: C - criança; E - examinadora; entre parênteses constam as ações da criança e entre colchetes comentários sobre o que está ocorrendo na interação.

5 Os nomes dos participantes que aparecem nesta e nas demais passagens são fictícios. 
quer colocar agora nove copos em cada bandeja. Veja que aumentou a quantidade de copos nas bandejas. Antes eram seis copos em cada bandeja e agora são nove copos em cada bandeja. A quantidade de bandejas vai aumentar ou diminuir?" [coloca em evidência as relações de covariação entre o tamanho da parte e o número de partes quando o dividendo, no caso o número de partes, é mantido constante].

C- Vai aumentar

E- Eu vou ter mais bandejas? Se eu colocar nove copos em cada bandeja eu vou ter mais bandejas? Ela quer colocar nove copos em cada bandeja. A quantidade de bandejas vai aumentar ou vai diminuir?

C- Diminuir

E- Muito bem! Por que vai diminuir a quantidade de bandejas? [busca explicação para que a criança explicite sua forma de raciocinar] C- Porque vai aumentar a quantidade de copos.

E- Muito bem! Vai aumentar a quantidade de copos nas bandejas e diminuir a quantidade de bandejas. Então, faz para nós vermos. [solicita que ela realize com os objetos para confirmar a sua resposta]

C- (resolve com os objetos)

E- Quantas bandejas ela vai precisar?

C- Duas

E- Então, se eu tenho a mesma quantidade de copos para distribuir nas bandejas e aumentar a quantidade de copos em cada bandeja, vai diminuir [criança completa a frase do examinador falando baixinho] “... diminuir a quantidade de bandejas." [explicita uma regra geral a respeito das relações de covariação entre o quociente e o divisor quando o dividendo é mantido constante].

Variação 2: "Viviane resolveu diminuir a quantidade de copos nas bandejas. Ela quer colocar agora três copos em cada bandeja. Veja que diminuiu a quantidade de copos nas bandejas. Antes eram nove copos em cada bandeja e agora são três copos em cada bandeja. A quantidade de bandejas vai aumentar ou diminuir?".

C- Vai aumentar.

E- Muito bem! Por quê? [busca explicação da forma de pensar da criança] C- Porque vai diminuir a quantidade de copos.

E- Isso mesmo, se eu tenho a mesma quantidade de copos para distribuir e diminuir a quantidade de copos em cada bandeja vai aumentar a quantidade de bandejas. E se eu tenho a mesma quantidade de copos para distribuir e eu aumentar a quantidade de copos nas bandejas vai...? [ressalta mais uma vez a atenção para as relações de covariação entre o quociente e o divisor quando o dividendo é mantido constante] 
C- Diminuir as bandejas.

E- Muito bem! Então, vamos fazer [solicita que a criança resolva com os objetos].

As intervenções da examinadora se caracterizaram por buscar da criança uma explicitação da sua forma de raciocinar ao resolver o problema (e suas variações) e por explicitar para a criança um dos invariantes do conceito de divisão, no caso, as relações inversas entre o tamanho das partes (número de copos em cada bandeja) e o número de partes (número de bandejas). Ao solicitar que a criança explicite sua forma de raciocinar e de resolver o problema, a examinadora tanto compreende a forma de pensar da criança como promove a tomada de consciência da criança acerca de sua própria forma de raciocinar.

\section{Passagem 2:}

Tão importante quanto saber as dificuldades das crianças, é examinar se elas são capazes de identificar erros quando se deparam com procedimentos incorretos de resolução que violam os princípios invariantes da divisão. A segunda passagem propiciava uma reflexão sobre o resto e sua relação com os demais termos da divisão através da apresentação de resoluções de problemas incorretas. Esses procedimentos incorretos foram documentados na literatura em pesquisas com crianças, a saber: o resto é ignorado durante o processo de resolução; o resto é inserido em uma das partes; o resto é distribuído em algumas das partes, mas não em outras; o resto é maior do que o número de partes. Esses procedimentos incorretos eram apresentados para os participantes sendo objeto de discussão. Material concreto era disponibilizado; no caso da passagem a seguir, fivelas e sacos plásticos eram colocados diante da criança.

Instrução dada pela examinadora: "Eu dei um problema de divisão para uma criança resolver e ela resolveu errado". Eu quero que você descubra o erro que ela fez. Primeiro vou ler o problema: 'Maria tem cinquenta fivelas de cabelo e quer colocá-las em oito saquinhos. Ela quer que cada saquinho tenha a mesma quantidade de fivelas. Quantas fivelas ela irá colocar em cada saquinho? 'Agora vou mostrar como foi que essa criança fez para resolver [resolve incorretamente o problema com os objetos, colocando cinco fivelas em cada saquinho e oito fivelas fora dos saquinhos, representando o resto]

E- O que foi que ela errou? [coloca o procedimento de resolução em evidência, tentando que a criança identifique a natureza do erro].

C- Pode consertar? (faz referência a manipular os objetos)

E- Primeiro, Fernanda, diz por que ela errou.

C- Porque ela não deu a mesma quantidade. 
E- Vamos contar nos saquinhos: um, dois, três, quatro, cinco... [conta em todos os saquinhos a quantidade de fivelas]... quantas fivelas tem em cada saquinho?

C- Cinco

E- Tem cinco fivelas em cada saquinho?

C- (silêncio)

E- Então, ela distribuiu a mesma quantidade. Se tem cinco aqui, cinco, cinco, cinco, cinco, cinco, cinco e cinco. Ela deu a mesma quantidade. [explicita que a resolução não está violando a igualdade entre as partes].

$\mathrm{O}$ que foi que ela errou?

C- (silêncio) Ela não colocou... não colocou as oito fivelas.

E- Como assim? [busca explicitação da forma de raciocinar da criança]. Explica melhor, eu não entendi... [pausa]. Ah! No problema dizia que eram oito fivelas?! Não! Maria tem cinquenta fivelas e quer colocá-las em oito saquinhos. [lê o problema novamente]

$\mathrm{C}-\mathrm{Ah}$ !

E- Ela colocou em oito saquinhos.

C- Aí tem quarenta. (refere-se às quantidades de fivela dentro dos saquinhos) [Não considera os elementos presentes no resto].

E- Tem quarenta e um, quarenta e dois, quarenta e três, quarenta e quatro, quarenta e cinco, quarenta e seis, quarenta e sete, quarenta e oito, quarenta e nove... cinquenta. [conta incluindo o resto] Aqui na mesa tem cinquenta fivelas. O que foi que ela fez errado? Vamos ver juntas.

C- Ela não guardou o resto. [reflete sobre o resto]

E- Ah! O que tem o resto? [solicita que explicite as bases do seu raciocínio a respeito do resto, especificamente].

C- Ela não usou.

E- Ah! Mas o que está acontecendo com o resto? Era para ele estar aqui? Qual o problema com o resto? [continua solicitando explicações a respeito da forma de pensar sobre o resto]

C- Porque se ela coloca o resto dentro de um saquinho vai ficar diferente... para os outros saquinhos. [preocupação em não violar a igualdade entre as partes]

E- Como assim, vai ficar diferente? [solicita explicitação mais detalhada sobre a forma de pensar a respeito da igualdade entre as partes]

C-Vai mudar a quantidade que tem dentro dos saquinhos. (opta por resolver com os objetos para confirmar sua resposta)

E- O que foi que você fez com o resto? [insiste na explicitação acerca do princípio que está sendo violado].

C- Eu usei. 
E- Então, o que tinha o resto? Ele estava...

C- Mais.

E- Maior do que o número de saquinhos e quando isso ocorre...

C- Tem que dividir.

E- Tem que dividir, fazer uma nova rodada de distribuição e um novo resto será produzido. Então, o resto não pode ser maior e nem...

C- Igual.

E- Isso mesmo! O resto não pode ser nem maior e nem igual ao número de partes ou tamanho da parte, quando isso ocorre tem que continuar a distribuição, e foi o que você fez. E quantas fivelas sobraram?

C- Duas.

E- Então, quantas fivelas ela irá colocar em cada saquinho?

C- Seis e vai sobrar duas.

E- O resto, ele pode sair fora da nossa representação? [enfatiza a relação do resto com a forma de resolver o problema para que ele não seja ignorado] C- Não!

E- Por quê?

C- Porque nós começamos a representar com eles, o número.

E- São cinquenta fivelas! Se eu tirar o resto eu vou ter cinquenta fivelas? [mostra que o resto faz parte do problema]

C- Não!

E- Eu vou ter quarenta e oito fivelas. Muito bem!

Assim como na Passagem 1, a examinadora sistematicamente solicitava que a criança explicasse a forma como estava pensando, explicitando, assim, as bases de seu raciocínio ao resolver o problema. Isso fazia com que a criança tomasse consciência de suas formas de raciocinar. O resto era, especificamente, colocado em evidência durante toda a interação com a criança, uma vez que a atividade tinha por objetivo exatamente levar a criança a lidar com o resto de maneira apropriada. Uma característica importante desta atividade era que a criança era solicitada a pensar sobre formas de resolução de problemas que, segundo as instruções da examinadora, haviam sido adotadas por outra criança. Esta é uma atividade metacognitiva pouco usual que propiciou que a criança refletisse sobre os procedimentos adotados por outra pessoa na resolução dos problemas. 


\section{Os resultados}

A resolução dos problemas no pré-teste e no pós-teste recebeu escores que variavam de zero a dois pontos: Zero ponto - a criança não resolve o problema ou interpreta de forma incorreta o enunciado verbal, podendo apresentar ou não encaminhamentos de resolução através de outras operações que não a divisão, adotando, na maioria das vezes, a adição e a multiplicação; Um ponto - a criança interpreta corretamente o enunciado verbal, considerando a divisão, porém erra na resolução porque: (a) inverte os valores do divisor e do quociente presentes no enunciado; ou (b) arma a operação de divisão, mas não finaliza a resolução; Dois pontos - a criança interpreta corretamente o enunciado verbal, apresenta estratégia de resolução correta e explicita a resposta. Também recebe essa pontuação a representação que apresenta somente a resposta correta possivelmente derivada de um cálculo mental e que explicita o referente para quantidade.

A Tabela 1 fornece uma visão geral do desempenho das crianças nas duas ocasiões de testagem.

TABELA 1 - NÚMERO E PERCENTUAL DE ACERTOS (ENTRE PARÊNTESES) EM CADA GRUPO NO PRÉ-TESTE E NO PÓS-TESTE

\begin{tabular}{ccccc}
\hline \multirow{2}{*}{ Pontuação } & \multicolumn{2}{c}{$\begin{array}{c}\text { Grupo controle } \\
(\mathrm{n}=600)\end{array}$} & \multicolumn{2}{c}{$\begin{array}{c}\text { Grupo experimental } \\
(\mathrm{n}=600)\end{array}$} \\
\cline { 2 - 5 } & Pré-teste & Pós-teste & Pré-teste & Pós-teste \\
\cline { 2 - 5 } Zero & 372 & 355 & 368 & 108 \\
& $(62 \%)$ & $(59 \%)$ & $(61 \%)$ & $(18 \%)$ \\
\multirow{2}{*}{ Um } & 186 & 177 & 196 & 260 \\
& $(31 \%)$ & $(30 \%)$ & $(33 \%)$ & $(43 \%)$ \\
Dois & 42 & 68 & 36 & 232 \\
& $(7 \%)$ & $(11 \%)$ & $(6 \%)$ & $(39 \%)$ \\
\hline
\end{tabular}

Observa-se que no pré-teste as crianças do grupo controle e do grupo experimental apresentam desempenho semelhante, obtendo um percentual bastante elevado de respostas incorretas ( $62 \%$ e $61 \%$, respectivamente) e um baixo percentual de respostas corretas ( $7 \%$ e $6 \%$, respectivamente). $O$ teste $\mathrm{U}$ de Mann-Whitney revelou que, de fato, os grupos não diferem significativamente no pré-teste $(Z=-0.042 ; \mathrm{p}=0.967)$.

No pós-teste, constata-se melhora no desempenho em ambos os grupos. Entretanto, esta melhora é mais expressiva para as crianças que participaram da intervenção (grupo experimental): elas apresentam um percentual de respostas corretas bem maior do que as crianças do grupo controle (GE: 39\% e GC: 11\%), 
mais delas recebem um ponto (GE: $43 \%$ e GC: $30 \%$ ) com percentual menor de respostas incorretas (GE: 18\% e GC: 59\%), em comparação ao desempenho das crianças do grupo controle. Esses resultados foram confirmados pelo teste $\mathrm{U}$ de Mann-Whitney que evidenciou diferença significativa entre o desempenho das crianças do grupo controle e do grupo experimental no pós-teste, com desempenho superior das crianças do grupo experimental $(\mathrm{Z}=-6.407, \mathrm{p}=0.000)$.

Observa-se, também, no pós-teste, que as crianças do grupo experimental reduzem o percentual de respostas incorretas de $61 \%$ para $18 \%$ e aumentam o percentual de respostas corretas de $6 \%$ para $39 \%$. Em contraste, no pós-teste, as crianças do grupo controle continuam com um percentual de respostas incorretas semelhante àquele observado no pré-teste $(59 \%$ e $62 \%)$ com melhora pouco expressiva no número de respostas corretas (de $7 \%$ no pré-teste para $11 \%$ no pós-teste).

Comparações entre o pré-teste e pós-teste em cada grupo foram feitas através do teste Wilcoxon. Como mostra a Tabela 1, não foram detectadas diferenças significativas entre o pré-teste e o pós-teste no grupo controle $(Z=-1.373 ; p$ $=0.170)$. Entretanto, no grupo experimental há diferenças significativas entre o pré-teste e o pós-teste $(Z=-5.948 ; p=0.000)$. Isso ocorreu porque no préteste havia um alto percentual de respostas incorretas e, após a intervenção, as crianças do grupo experimental aumentaram o percentual de respostas corretas, demonstrando ter desenvolvido maior compreensão acerca da divisão, indicando um efeito positivo da intervenção realizada.

Análises complementares mostram que intervenção teve um efeito mais expressivo sobre a compreensão acerca do resto do que acerca das relações inversas entre os termos da divisão. Uma possível explicação para isso é que o resto é algo mais evidente do que as relações entre os termos da divisão; é mais fácil então tomá-lo como objeto de reflexão e análise do que aquelas relações, as quais resultam de uma comparação realizada mentalmente pela criança que não pode ser tratada da mesma forma que o resto.

\section{Discussão e conclusões}

Um primeiro aspecto a ser mencionado é o fato de que a intervenção favoreceu a compreensão da criança acerca da divisão. Porém, o foco da discussão aqui conduzida recai mais sobre a forma como a intervenção foi conduzida do que sobre os resultados dela derivados. É evidente que se a intervenção não houvesse sido bem-sucedida, não seria necessário discutir a respeito das 
interações ocorridas durante as sessões de intervenção como foi feito neste trabalho; porém, o que se deseja discutir nesta parte final do artigo é a natureza da intervenção proposta como um exemplo das possíveis relações entre metacognição e aprendizagem.

Um primeiro comentário refere-se à tomada de consciência. Ao explicitar, a pedido do adulto, as bases de seus julgamentos e sua maneira de raciocinar ao resolver problemas (semelhante ao que ocorre em entrevistas clínicas nos moldes piagetianos), a criança pode tomar consciência de suas formas de pensar naquela situação, sejam elas apropriadas ou não. O pensamento, então, torna-se objeto de reflexão e análise pela criança. Mas não só pela criança, como também pelo adulto que com ela interage; de forma que ambos, como ilustrado nos exemplos descritos anteriormente, passam a discutir os procedimentos empregados na resolução dos problemas.

Um segundo comentário é que, uma vez instaurada a tomada de consciência, a criança pode, então, compreender o que fez, compreender como o fez e compreender porque o fez. Mecanismos de autorregulação e controle poderão, assim, participar deste cenário de reflexão, permitindo que a criança monitore a situação, faça os ajustamentos necessários, avalie a adequação de suas posições e as altere se necessário.

Implicações educacionais relativas ao ensino da divisão podem ser extraídas da pesquisa descrita neste artigo, assim como implicações educacionais mais amplas relativas ao ensino de matemática de maneira geral.

Sobre o ensino da divisão, as implicações podem apontar para ser interessante iniciar-lo a partir da resolução de problemas envolvendo divisão inexata porque a presença do resto pode ser um recurso didático importante para levar a criança a compreender os demais termos da divisão. Assim, ela não mais violaria um dos princípios desse conceito que é a igualdade do tamanho das partes em que o todo foi dividido.

A respeito da educação matemática de maneira mais ampla, a implicação de natureza didática está no fato de que o ensino pode envolver atividades de natureza metacognitiva em que o aluno é colocado simultaneamente na condição de ator e expectador de suas formas de raciocinar. O papel do professor é extremamente ativo, pois, como mencionado por Spinillo (1999; 2003), dificilmente a criança por si mesma seria capaz de se colocar como expectadora de seu pensamento, tomando-o para reflexão e análise. Cabe ao professor desenvolver a cultura do pensar na sala de aula, convocando os alunos a explicitar suas formas de raciocinar, tornando-as passíveis de serem compartilhadas, discutidas e comparadas (com as dos colegas ou com as do próprio professor), criando um clima de discussão na sala de aula, colocando o pensamento do aluno em evidência. Ainda sobre o papel do professor, parece ser necessário que 
a explicitação verbal também permeie a explicitação dos princípios que regem os conceitos matemáticos. Isso foi feito nesta pesquisa em relação à divisão, porém tal explicitação pode ser conduzida a respeito de qualquer outro conceito matemático (ver SPINILLO, 2003 a respeito dos princípios que governam o conceito de proporção).

Para finalizar, segundo Ribeiro (2003, p. 114), as intervenções "que contemplam, além de atividades cognitivas, atividades metacognitivas, têm originado melhores resultados em termos de realização escolar." A metacognição, no que se refere à aprendizagem, pode vir a assumir papel importante dentro da sala de aula.

\section{REFERÊNCIAS}

BORUCHOVITCH, E. Algumas estratégias de compreensão da leitura de aluno de ensino fundamental. Psicologia Escolar e Educacional, v. 5, n. 1, p. 19-26, 2001.

CARDELLE-ELAWAR, M. Effects of teaching metacognitive skills to students with low mathematics ability. Teaching and Teacher Education, v. 8, n. 2, p. 104-121, 1992.

. Effects of metacognitive instruction on low achievers in mathematics. Teaching and Teacher Education, v. 11, n. 1, p. 81-95, 1995.

CHAHON, M. O uso da metacognição no ensino fundamental de matemática: uma proposta de intervenção. Arquivos Brasileiros de Psicologia, v. 51, n. 3, p. 52-59, 1999.

COLE, M.; JOHN-STEINER, V.; SCRIBNER, S.; SOUBERMAN, E. Vygotsky. A formação social da mente. Tradução de: NETO, J. C.; BARRETO, L. S. M.; AFECHE, S. C. São Paulo: Martins Fontes, 1978.

DAVIS, C.; NUNES, M. M.; NUNES, M. M. Sucesso escolar: articulando teoria e prática. Cadernos de Pesquisa, v. 35, n. 125, p. 205-230, 2005.

FLAVELL, J. H. Metacognitive aspects of problem solving. In: RESNICK, L. B. (Orgs.). The nature of intelligence. Hillsdale, N.Y.: Erlbaum, 1976. p. 231-235.

Metacognition and cognitive monitoring: A new area of cognitivedevelopmental inquiry. American Psychologist, v. 34, n. 10, p. 906-911, 1979. 
. Speculations about the nature and development of metacognition. In: WEINERT, F. E.; KLUWE, R. (Orgs.). Metacognition, motivation, and understanding. Hillsdale, N. J.: Erlbaum, 1987. p. 1-16.

GOLDBERG, P. Increasing problem solving through the metacognitive skills of planning, monitoring and evaluating. Relatório de pesquisa. Henry County/Ken: The Spencer Foundation. From ERIC database, 1999.

JOU, G. I. I. de; SPERB, T. M. A metacognição como estratégia reguladora da aprendizagem. Psicologia Reflexão e Crítica, v. 19, n. 2, p. 177-185, 2006.

LEFFA, V. Aspectos de leitura: uma perspectiva psicolinguística. Porto Alegre: Sagra, 1996.

MAVARECH, Z.; KRAMARSKI, B. The effects of metacognitive training versus worked-out examples on students' mathematic reasoning. The British Journal of Educational Psychology, v. 73, n. 4, p. 449-471, 2003.

MORO, M. L. F. Estruturas multiplicativas e tomada de consciência: repartir para dividir. Psicologia: Teoria e Pesquisa, v. 2, n. 21, p. 217-226, 2005.

PIAGET, J. A tomada de consciência. Tradução de: SOUZA, E. B. de. São Paulo: EDUSP/ Melhoramentos, 1977.

. Fazer e compreender. Tradução de: LEITE, C. L. de P. São Paulo: EDUSP/ Melhoramentos, 1978.

RIBEIRO, C. Metacognição: um apoio ao processo de aprendizagem. Psicologia Reflexão e Crítica, v. 16, n. 1, p. 109-116, 2003.

ROZENCWAJG, P. Metacognitive factors in scientific problem-solving strategies. European Journal of Psychology of Education, v. 18, n. 3, p. 281-294, 2003.

SEMINÉRIO, F. L.; ANSELME, C. R. S.; CHAHON, M. Metacognição: um novo paradigma. Arquivos Brasileiros de Psicologia, v. 51, n. 1, p. 110-126, 1999.

SPINILLO, A. G. As relações entre aprendizagem e desenvolvimento discutidas a partir de pesquisas de intervenção. Arquivos Brasileiros de Psicologia, v. 51, n. 1, p. 55-74. 1999.

. G. Ensinando proporção a crianças: alternativas pedagógicas em sala de aula. Boletim GEPEM Grupo de Estudos e Pesquisas em Educação Matemática, v. 43, n. 3, p. 11-47, 2003. 
. O leitor e o texto: desenvolvendo a compreensão de textos na sala de aula. Interamerican Journal of Psychology, v. 42, n. 1, p. 29-40, 2008.

STERnBERG, R. Psicologia cognitiva. Tradução de: BORGES, M. R. Porto Alegre: Artes Médicas, 2000. 
